\title{
PULMONARY ALVEOLAR PROTEINOSIS IN A MARBLE WORKER
}

\section{BERNA BOTAN YILDIRIM ${ }^{1}$, RECEP AKGEDIK ${ }^{1}$, SUKRAN AKGEDIK ${ }^{2}$, and HASAN NAZAROGLU ${ }^{3}$}

${ }^{1}$ Ordu University Education and Research Hospital, Ordu, Turkey

Department of Pulmonology

${ }^{2}$ Ordu Government Hospital, Ordu, Turkey

Department of Pathology

${ }^{3}$ Ordu University Education and Research Hospital, Ordu, Turkey

Department of Radiology

\begin{abstract}
Pulmonary alveolar proteinosis (PAP) is a rarely seen disease of the alveoli, characterized by accumulation of proteinous material, which stains positive with periodic acid Schiff, in the alveoli. Secondary PAP may develop as a result of occupational exposure to materials such as silica and indium. In the paper, together with a review of the relevant literature, we present an uncommon case of a 47-year old male, marble worker who was diagnosed with PAP associated with a 12-year history of exposure to marble dust. Int J Occup Med Environ Health 2016;29(5):871-876
\end{abstract}

Key words:

Silica, Occupational disease, Bronchoalveolar lavage, Pulmonary alveolar proteinosis, Marble worker, Rare lung disease

\section{INTRODUCTION}

Pulmonary alveolar proteinosis (PAP) is a rarely seen disease, which impairs gas exchange in the alveoli and is characterized by progressive accumulation of surfactants, phospholipids and proteins in the alveoli and terminal airways. Pulmonary alveolar proteinosis was first described by Rosen, Castleman and Liebow in 1958 [1].

It is categorized into 2 forms: congenital and acquired. The acquired form is subdivided into 2 forms of autoimmune and secondary forms, which include those associated with malignancies, especially hematolymphoid malignancies, immunodeficiency disorders, infectious diseases, uncommonly as a drug reaction, and those caused by occupational exposure [2]. The majority of PAP cases are of the autoimmune form. However, there are cases of secondary PAP reported due to occupational exposure to silica, indium and various toxic inhalation injuries $[3,4]$. The case presented here is a rarely seen diagnosis of PAP associated with marble work.

\section{CASE}

A 47-year old male presented at our hospital with complaints of fatigue and a non-productive cough, which had been ongoing for 3 months. He had no significant medical history. There was a history of active cigarette smoking of 22 pack-years. The patient worked in a marble factory

Received: June 26, 2015. Accepted: November 25, 2015.

Corresponding author: B.B. Yildirim, Ordu University Education and Research Hospital, Department of Pulmonology, Bucak Quarter, Nefsi Bucak Street, 52200 Ordu, Turkey (e-mail: mdberna2001@yahoo.com). 

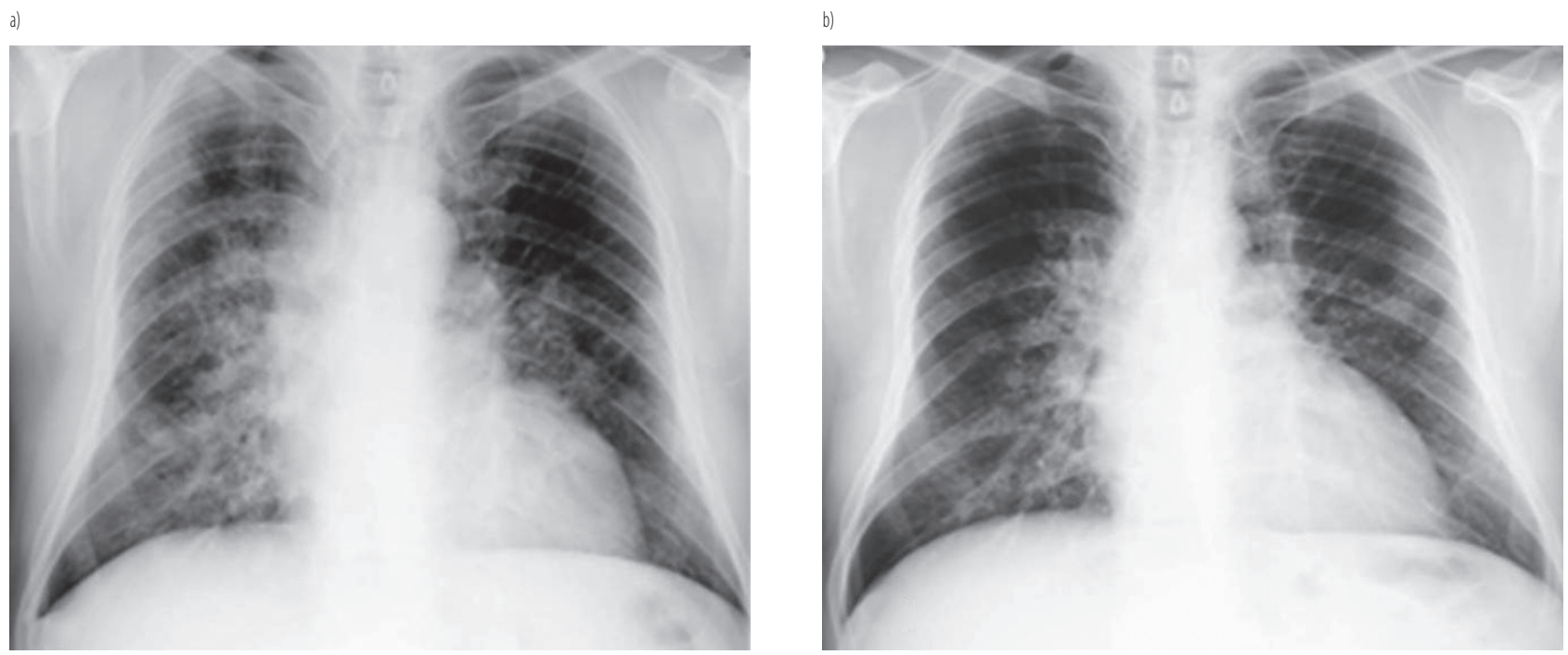

Photo 1. a) Bilateral reticulonodular opacity in the pulmonary radiograph, b) chest X-ray after 6 months

between 1999-2011. Since 2011 he has been working as a fisherman. He had no additional history of environmental exposure or hobbies. There was nothing remarkable in the family history.

In the physical examination, blood pressure was $110 / 70 \mathrm{~mm} \mathrm{Hg}$, heart rate $89 / \mathrm{min}$, temperature $36.8^{\circ} \mathrm{C}$, peripheral capillary oxygen saturation $\left(\mathrm{SpO}_{2}\right) 97 \%$. There were widespread rhonchi, with no cyanosis or no finger clubbing. Other system examinations results were normal. In the laboratory examination, sedimentation rate was $76 \mathrm{~mm} / \mathrm{h}$.

The complete blood count, urine test and biochemical parameters (including lactate dehydrogenase - LDH) were normal. Sputum was negative for acid-resistant bacilli (ARB), Gram staining and culture. The antinuclear antibodies (ANA), anti-double-stranded DNA antibodies (anti ds-DNA), perinuclear anti-neutrophil cytoplasmic antibodies (p-ANCA), cytoplasmic antineutrophil cytoplasmic antibodies (c-ANCA), angiotensin-converting enzyme (ACE) and rheumatoid factor (RF) levels were normal. In the arterial blood gas tests, partial pressure of oxygen $\left(\mathrm{pO}_{2}\right)$ was $78 \mathrm{~mm} \mathrm{Hg}$, partial pressure of carbon dioxide $\left(\mathrm{pCO}_{2}\right)-41.7 \mathrm{~mm} \mathrm{Hg}$ and saturation (SAT) - 97.3\%. However, results of the respiratory function tests were abnormal: forced vital capacity (FVC) - 3.161 (79\% of predicted value), forced expiratory volume in $1 \mathrm{~s}\left(\mathrm{FEV}_{1}\right)-3.13$ (96\% of predicted value). The diffusing capacity of the lungs for carbon monoxide $\left(\mathrm{DL}_{\mathrm{CO}}\right)$ was reduced, being $78 \%$.

On the pulmonary radiograph, bilateral reticular infiltrations were observed (Photo 1a). In high resolution computed tomography (CT) images, crazy-paving in the perihilar area of both lungs and more in the upper peripheral zone was visible (Photo 2). No endobronchial lesions were observed in bronchoscopy.

Bronchoalveolar lavage fluid (BALF) was taken from the right upper and mid lobes and a transbronchial biopsy was taken from the right upper lobe anterior segment. The BALF was cream colored with a milky appearance. Acid-resistant bacilli (ARB) in the BAL fluid were negative for Gram staining and no growth was seen in the culture. In the cytological examination of BALF, dense acellular eosinophilic amorphous material (Photo 3 ) and periodic acid Schiff (PAS)-stained macrophages (Photo 4) were seen. The results of lavage were consistent with PAP. With a typical radiological appearance and cytological 


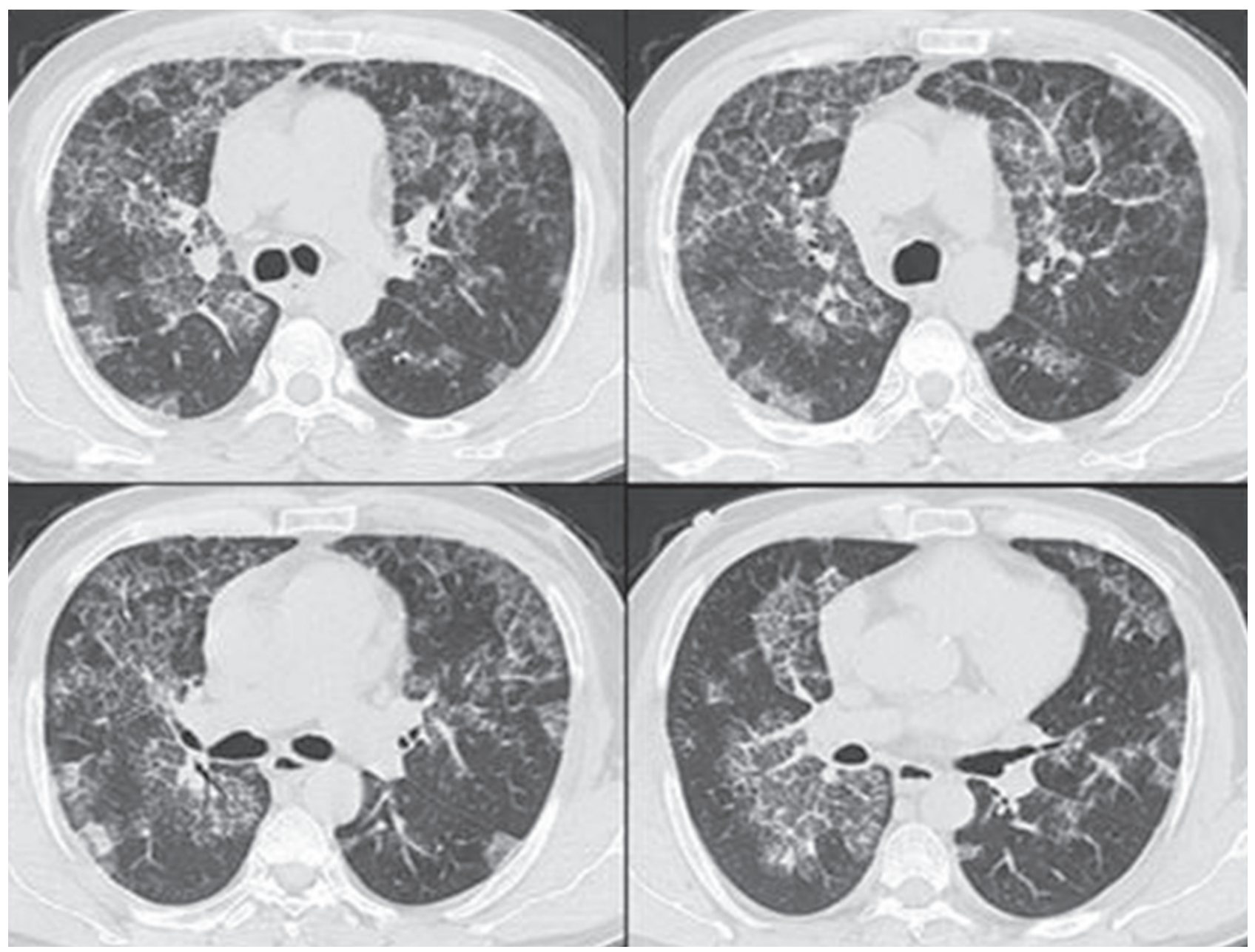

Photo 2. Crazy-paving appearance in the perihilar area and more in the peripheral upper zone of both lungs on high-resolution computed tomography

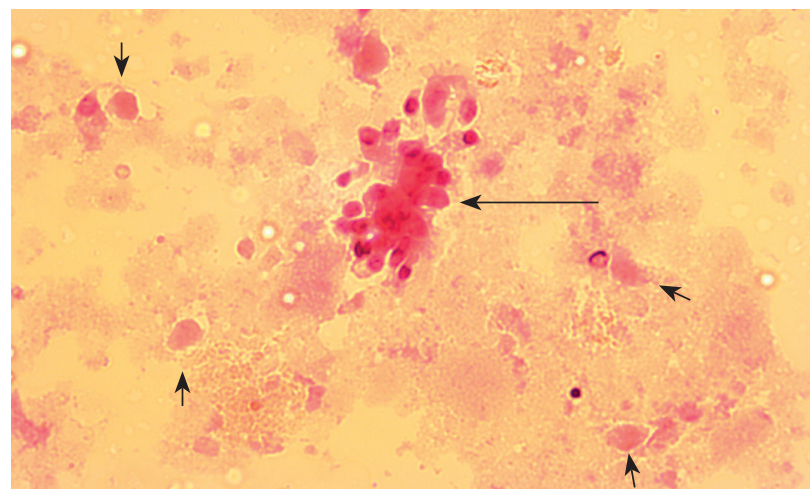

Photo 3. Degenerative bronchial epithelial cells (long arrow) and numerous eosinophilic amorphous protein material (short arrows) in the cytological examination of bronchoalveolar lavage fluid $(\mathrm{H} \& \mathrm{E}$ staining, magnification $\times 40)$

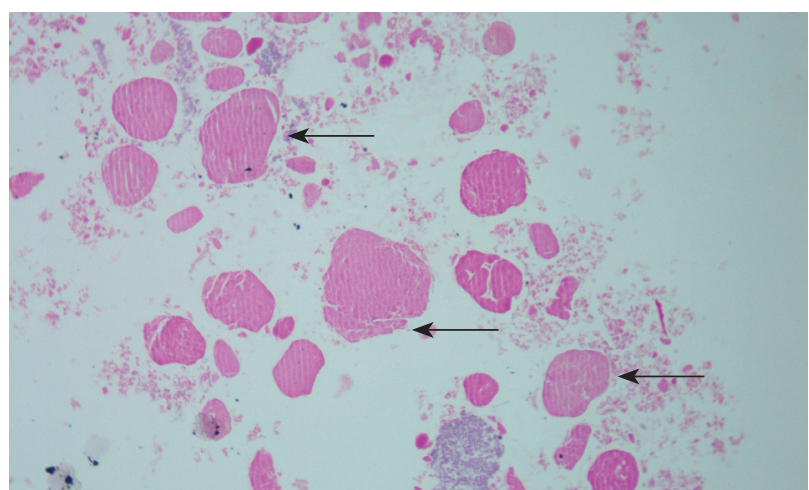

Photo 4. Amorphous protein material (arrows)

in the cytological examination of bronchoalveolar lavage fluid (periodic acid Schiff $(\mathrm{PAS}) \times 200$ ) 
findings, a diagnosis of PAP was made. The patient had no hypoxemia in the arterial blood gas, no dyspnea but the results of respiratory function tests were slightly reduced. The patient has been subjected to a follow-up without any medical treatment for 1 year, and there has been no progression. A regression was determined after 6 months on the pulmonary radiograph (Photo 1b). The follow-up is still ongoing.

\section{OCCUPATIONAL HISTORY}

Marble stone crafting is a small-scale industry in Turkey. There are different colors and patterns of limestone, granite, igneous origin of rocks (diorite, gabbro, diabase, etc.), with large travertine and onyx marbles. When working with dust, workers should wear protective masks to prevent inhalation of respirable particles. Unfortunately, in terms of occupational health, safety in our country is still not sufficient. In most of the facilities in our country, sufficient protective precautions against occupational dusts are usually not provided. The patient said that none of the workers used mask-protection at the facility. He had been working in the white marble block cutting section for 12 years. Artificial marble was not handled at the facility. No data was provided about the dust density or silica contents since no occupational health and safety specialist was available at the facility.

\section{DISCUSSION}

Pulmonary alveolar proteinosis is a rarely seen disease, in which surfactant secreted from the excessive amount of type II pneumocytes and/or inadequate removal of surfactant from the environment by alveolar macrophages play a role in the pathophysiology [5]. It is categorized into 2 main groups: congenital or acquired. The acquired group, which forms the larger patient group, is subdivided into the autoimmune subtype related to granulocyte macrophage colony stimulating factor antibody (GM-CSF), and the secondary subtype - associated with an underlying reason. Acquired autoimmune diseases constitute the vast majority of cases [5-7].

Secondary PAP is associated with haematological disease, immune insufficiency and chronic inflammatory syndromes, cancer and inhalation of organic and inorganic dust such as silica $[3,4,6]$. In this form of PAP, either alveolar macrophages are few in number or the functions are impaired [6,7]. In the tests applied to the current case, there was no infection, malignancy, history of medication use or autoimmune disease, which would explain etiology of the disease.

Marble is mainly composed of calcium carbonate $\left(\mathrm{CaCO}_{3}\right)$. Marble dust can be regarded as a low-toxicity particulate matter. In the literature, there are few papers about marble dust-related pulmonary diseases [8-13]. Although marble dust is not considered to be fibrogenic dust, it contains silica in different ratios. Silica causes various pathologies ranging from irritation of the upper respiratory airways to pneumoconiosis. Although few in number, there are reports in literature of silica-associated PAP cases [4]. In the current case, no other effective factor other than exposure to marble dust was determined.

Clinical findings of PAP are non-specific, with coughing and dyspnea as the most frequently observed symptoms. In the restrictive type, respiratory function is impaired and a reduction in lung volume and diffusion capacity is seen. In the current case, there was a slight reduction in diffusion capacity and the respiratory function tests were suggestive of restrictive impairment.

Radiologically, in high-resolution CT (HRCT), ground glass opacity in a mottled fashion accompanied by interlobular and intralobular septal thickening is known as a crazy-paving pattern. According to the HRCT findings, heart failure, infections and alveolar hemorrhage are primarily taken into consideration in a differential diagnosis. Our patient's age, clinical and radiological findings were not compatible with heart failure since the cardiothoracic ratio was normal in the X-ray. Moreover, the patient had 
no paroxysmal nocturnal dyspnea and orthopnea. Because the clinical features were not consistent with an infectious process and there was absence of laboratory evidence, infection was ruled out. Taking into account mild symptoms, lack of anemia and no history of hemoptysis, alveolar hemorrhage was also excluded.

Bronchoalveolar lavage fluid is extremely important in the diagnosis of PAP, as together with typical radiological appearance, milk-like opacity of lavage fluid is a diagnostic feature [4]. In the BAL cytopathological examination, presence of PAS-positive granules and eosinophilic material is significant for diagnosis. In cases of inconclusive diagnosis, open pulmonary biopsy is the gold standard. In the current case, besides a typical radiological appearance, the bronchoscopic lavage material was of a dense and opaque color. In the cytopathological examination of the lavage material, PAS-positive stained macrophages were observed.

In $10-50 \%$ of cases of patients suffering from this disease they recover spontaneously $[1,14,15]$, and sometimes the disease progresses with relapses and remissions. The treatment varies depending on the subgroup and the severity of the disease. While supportive treatment is sufficient in moderate disease, in severe cases treatment may go as far as lung transplantation [7].

The current standard treatment is the repeated whole lung lavage. Alternative treatment choices are: inhalation of GM-CSF aerosol, subcutaneous GM-CSF injection, plasmapheresis and rituximab. Treatment is not necessary for every patient. At the time of diagnosis, cases without hypoxemia and those where activities are not inhibited may be followed up without any treatment. The most effective treatment of secondary PAP also removes the underlying cause [7]. As the current case did not have any of the criteria mentioned above, it was decided to remove the patient from exposure to marble dust and to perform a follow-up without any treatment. For 1 year there has been no medical treatment and no progression of the disease. The follow-up is being continued.
In conclusion, this case of PAP in a marble worker may probably be attributed to his occupational exposure to marble dust. In the absence of information about the contents of crystalline silica in the marble, it is not clear whether this represents a novel cause of PAP or another example of silica-induced PAP. Although it is an uncommon disease, when respiratory symptoms and a typical radiological appearance are determined in workers from this sector, as it was in the current case, PAP should be kept in mind.

\section{REFERENCES}

1. Rosen SH, Castleman B, Liebow AA. Pulmonary alveolar proteinosis. N Engl J Med. 1958;258(23):1123-42.

2. Trapnell BC, Nakata K, Kavuru MS. Pulmonary alveolar proteinosis syndrome. Chapter 63. In: Mason RJ, Broaddus VC, Martin TR, King TE, Schraufnagel DE, Murray JF, et al., editors. Muray and Nadel's textbook of respiratory medicine. 5th ed. Vol. II. Philadelphia: Elsevier; 2010. p. 1516-36.

3. Cummings KJ, Nakano M, Omae K, Takeuchi K, Chonan T, Xiao YL, et al. Indium lung disease. Chest. 2012 Jun; 141(6):1512-21, http://dx.doi.org/10.1378/chest.11-1880.

4. Sauni R, Järvenpää R, Livonen E, Nevalainen S, Uitti J. Pulmonary alveolar proteinosis induced by silica dust. Occup Med. 2007;57:221-4, http://dx.doi.org/10.1093/occmed/ kql162.

5. Trapnell BC, Whitsett JA, Nakata K. Pulmonary alveolar proteinosis. N Engl J Med. 2003;349:2527-39, http://dx.doi. org/10.1056/NEJMra023226.

6. Borie R, Danel C, Debray MP, Taille C, Dombret M-C, Aubier M, et al. Pulmonary alveolar proteinosis. Eur Respir Rev. 2011;20:120-98,http://dx.doi.org/10.1183/09059180.00001311.

7. Khan A, Agarwal R. Pulmonary alveolar proteinosis. Respir Care. 2011;56:1016-28, http://dx.doi.org/10.4187/respcare. 01125 .

8. Leikin E, Zickel-Shalom K, Balabir-Gurman A, Goralnik L, Valdovsky E. Caplan's syndrome in marble workers as occupational disease. Harefuah. 2009;148(8):524-6,572. 
9. Camici G, Castagna P, Leva G, Messina S, Poletti GF, Vergazzoli PC. Environmental health risks in a marble-working shop. Ann Ist Super Sanita. 1978;14(3):547-51.

10. Sedov KR, Shcherbitskaia ZJ, Fedorova VI. [Clinicomorphological characteristics of pneumoconiosis caused by marble dust from a mica deposit]. Gig Tr Prof Zabol. 1973;17(10):47-9. Russian.

11. Vigliani EC. Possibility of production of silicosis by inhalation of white marble dust. Folia Med (Napoli). 1953;36(2):74-9.

12. Sezgi C, Abakay O, Önder H, Selimoğlu Şen H, Abakay A, Kaya $\mathrm{H}$, et al. [The respiratory functions and radiologic findings of the marble factory workers]. J Clin Exp
Invest. 2012;3(2):250-4, http://dx.doi.org/10.5799/ahinjs.01. 2012.02.0153. Turkish.

13. Orman A, Ünlü M, Cirit M, Yücel A. [Respiratory symptoms, pulmonary function tests and chest X-rays in marble workers]. Türk Toraks Derneği. 2002;3(2):188-93. Turkish.

14. Seymour JF, Presneill JJ. Pulmonary alveolar proteinosis: Progress in the first 44 years. Am J Respir Crit Care Med. 2002;166:215-35, http://dx.doi.org/10.1164/rccm.2109105.

15. Kariman K, Kylstra JA, Spock A. Pulmonary alveolar proteinosis: Prospective clinical experience in 23 patients for 15 years. Lung. 1984;162:223-31, http://dx.doi.org/10.1007/ BF02715650.

This work is available in Open Access model and licensed under a Creative Commons Attribution-NonCommercial 3.0 Poland License - http://creativecommons.org/ licenses/by-nc/3.0/pl/deed.en. 